\title{
The Role of the United States-Greek Initiative for Technology Cooperation with the Balkans in Constructing a Unified Environmental Technology Plan
}

\author{
Nicholas A. Ashford and Christi Electris
}

This article argues that the co-evolution of environmental and industrial policies through a realistic melding of those concerns in sustainable development policies and practices is crucial. Furthermore, the authors are convinced that this requires a unified environmental technology plan for the Balkans that will be enhanced by European Union integration requirements. An initiative that can facilitate this effort-the joint United States-Greek Initiative for Technology Cooperation with the Balkans (the ITCB), is described.

\section{Introduction}

The Balkans, on the southeast flank of the European Union (EU), are undergoing historical, political, cultural and economic change. While some countries are on their way to joining the EU, others have that goal clearly in mind. It is the only logical strategic goal for countries formerly ravaged by war, environmental destruction, inadequate economic and political development, and neglected by the United States and Europe for far too long. The Treaties of Maastricht and Amsterdam have brought a new focus to the meaning of membership of the EU in terms of the pursuit of environmental improvement and sustainable development. Environment is asserted to no longer be an afterthought in the development of EU policies; it is arguably central to the conduct of commerce, trade and development. This has significant implications for environmental policies in the region.

Correspondence to: Nicholas A. Ashford, Professor of Technology and Policy, Director, MIT Technology and Law Program, Massachusetts Institute of Technology, MIT E40-239, 77 Mass Ave., Cambridge, MA 02139, USA. Email: nashford@mit.edu 
There might have been a time when the development of environmental policy in the Balkan countries simply would have meant that each country in the region be engaged, more or less, in the monitoring of environmental quality, the adoption of a national regulatory regime consistent with cultural norms and the inevitable relaxation of environmental measures to meet domestic economic demands. The fact that the would-be accession countries to the EU must have their environmental regimes established in law prior to accession, and the realization that many environmental problems are crossborder (as in the case of shared waters) and require cooperation for optimal management, provides an opportune challenge for the region to coordinate, if not integrate, their environmental regimes. Some countries in the region are more advanced than others in terms of their knowledge base, technical capacities and regulatory systems. Unlike other regions that are destined to increase their commercial and economic integration, the Balkans is one region where 'a race to the bottom' is unlikely with the EU establishing increasingly stringent environmental performance improvements.

This article argues that the co-evolution of environmental and industrial policies through a realistic melding of those concerns in sustainable development policies and practices is crucial. Furthermore, we are convinced that this requires a unified environmental technology plan for the Balkans. Europe plays a central role here, but so may a little-known joint United States-Greek Initiative for Technology Cooperation with the Balkans (the ITCB). In the remainder of this article, we describe the ITCB, and discuss briefly the state of the environment and environmental technology capacities in the region and the approach of the ITCB in developing an environmental technology plan for the Balkans.

\section{History and Purposes of the ITCB}

As a result of direct negotiations in 1997, former President Bill Clinton and former Greek Prime Minister Costas Simitis jointly proposed the establishment of the United States-Greek Initiative for Technology Cooperation with the Balkans (the ITCB). The ITCB was established in order to: (1) promote economic stability, restore peace and facilitate peaceful transition to free enterprise economies in the Balkan Region; (2) strengthen the friendship and understanding in the relationships of American and Greek private-sector firms and private and public entities in the Balkan Region; (3) provide economic benefits to the Balkan Region; and (4) promote collaboration and cooperation among technology and industrial organizations, researchers and engineers for the benefit of the Balkan region.

A memorandum of understanding between the founding governments was signed in January 1998 and a six-person intergovernmental American-Greek Council was established and charged with implementing initiatives of the ITCB. The Joint Council, composed of academic and business members, identified as top priorities bilateral efforts focused on the Balkans to improve the environment, information and communication technology (ICT), food processing, and agricultural infrastructure in the region. Other areas were to be developed as needed. The American and Greek bilateral efforts were intended to emphasize the creation of multilateral partnerships with the 
countries of the Balkan region involving private and public sector institutions and persons, academic/research institutions and other multilateral initiatives in bringing and developing technologies to benefit nations of the region, with initial emphasis on Albania, Bulgaria, the Former Yugoslav Republic of Macedonia (FYROM) and Romania. In 2003, the Council unanimously agreed to expand the countries of interest to Serbia and Montenegro (two countries since spring 2006). Bosnia and Herzegorina has now also been added to the list of target countries.

The Council's aim is not limited to providing contact between American and Greek institutions and their various Balkan counterparts. It also serves as a discussion forum and information transfer source for new ideas about enhancing the region's technological opportunities and capabilities. Both private sector partnerships and public-private ventures are expected to help stabilize and develop the region through meeting the essential needs of the people of the region. Greece is in a unique geopolitical position to assist in both confidence-building and capacity-building measures with the Albanian, Slavic and other peoples to its north.

Several key points about the ITCB initiative deserve emphasis. First, while the private sector is seen as the dominant and an indispensable vehicle for technology transfer to the Balkans, the beneficiaries must be understood as being the people of the region. For this reason, a 'technology needs assessment' for all four areas of interest (including the environment) was undertaken under the leadership of Professor Iacovos Vasalos at the Technology Park in Thessaloniki-the designated Greek Secretariat for the ITCB. Second, the approach is not meant to be 'top down', but needs to involve the various stakeholders: industry, all levels of government, scientists and academics, nongovernmental organizations and labor organizations. (It is important to note that academics in the region are very often technology business stakeholders as well.) In order for the initiative to be successful, the stakeholders need to 'own' the various projects. Getting the different stakeholders to reach a consensus in a region where consensus is a foreign concept is no small challenge. The building of a strong, law-based civil society is essential in this regard. For example, in the environmental area, regulatory systems and technical assistance capacities appropriate to the culture of the Balkan region need to be established and coordinated.

Third, aside from individual projects, emphasis will be put on capacity-building and self-reliance that goes beyond specific projects. A fourth point is that the emphasis is intended to be on Technology for Sustainable Development in terms of three dimensions: the establishment and growth of enterprises and markets; environmental and public health improvements; and creation and improvements in the labor markets. Fifth, the establishment and strengthening of both public and private sector infrastructure deserves a central focus including, but not limited to: vehicles for micro-, meso- and macro-credit; confidence- and consensus-building; environmental and resource management laws and institutions; and transportation. 'Leap-frogging' needs to be conceptualized both in terms of specific technology adoption and in terms of institutional and individual capacity-building.

Sixth, an important enabling element in the ultimate success of the ITCB initiative is education from grammar school to vocational schools to universities. While education 
is beyond the specific charge of the ITCB, Greece itself is in a unique position to help build English-language literacy and create institutions that depend on instruction in a variety of fields, using English as a potential unifying factor in the Balkans. More directly related to its mission is the training of science/technology policy analysts and designers to staff public and private sector initiatives for technology transfer and development to aid the Balkan region. Seventh, the long-range expansion of the EU to include the countries of the region is in the interests of both the United States and Greece. The ITCB initiative is intended to be coordinated with efforts of the EU and other activities already underway, such as those of the United Nations Environment Programme, the Southeastern European Cooperative Initiative and the Stability Pact for Southeastern Europe. Rather than a program of activity that competes with these much larger efforts, the ITCB should be seen as a catalyst and broker among the different initiatives and stakeholders. Finally, American-Greek and public-private partnerships are key elements of success, but it must be recognized that a central concern of the private sector is security of investment, a supporting infrastructure for the delivery of goods and services, and legal norms and institutions.

\section{The Environmental Situation in the Balkans}

A preliminary evaluation of the situation in the Balkans is found in Table 1. The reader is also referred to an earlier environmental audit found on the websites of the ITCB (see the website of the Greek ITCB Secretariat (http://www.itcb.gr) or the link with the United States Department of Commerce Technology Administration, the American sponsor of the ITCB (http://www.technology.gov/International/Europe/ ITCB.html).

\section{An Environmental Technology Plan for the Balkans}

The ITCB is engaged in initial research in developing an environmental technology plan for the Balkans. The focuses of this approach are to: identify key technical environmental problems related to agricultural and industrial activities in the Balkans; evaluate the technological gaps, capabilities and capacities these countries have in addressing those problems; describe and assess the regulatory infrastructure needs and capacities; and identify options for knowledge and technology transfer. The research explores technical, management and legal approaches for improving the environment and developing/adopting appropriate environmental technology in the Balkans through joint American-Greek initiatives, activities of the EU, private aid and Balkanwide institutional cooperation and integration.

The study will explore the following issues in the Balkans: common technical and development problems of pollution such as water, waste and air, pesticides, unsustainable industrialization and agriculture; common governance and management problems such as the lack of an adequate regulatory system, a tradition of ignoring legal norms and no adequate knowledge infrastructure and institutions; and the potential benefit of the development of a joint Balkan-wide environmental technology management 


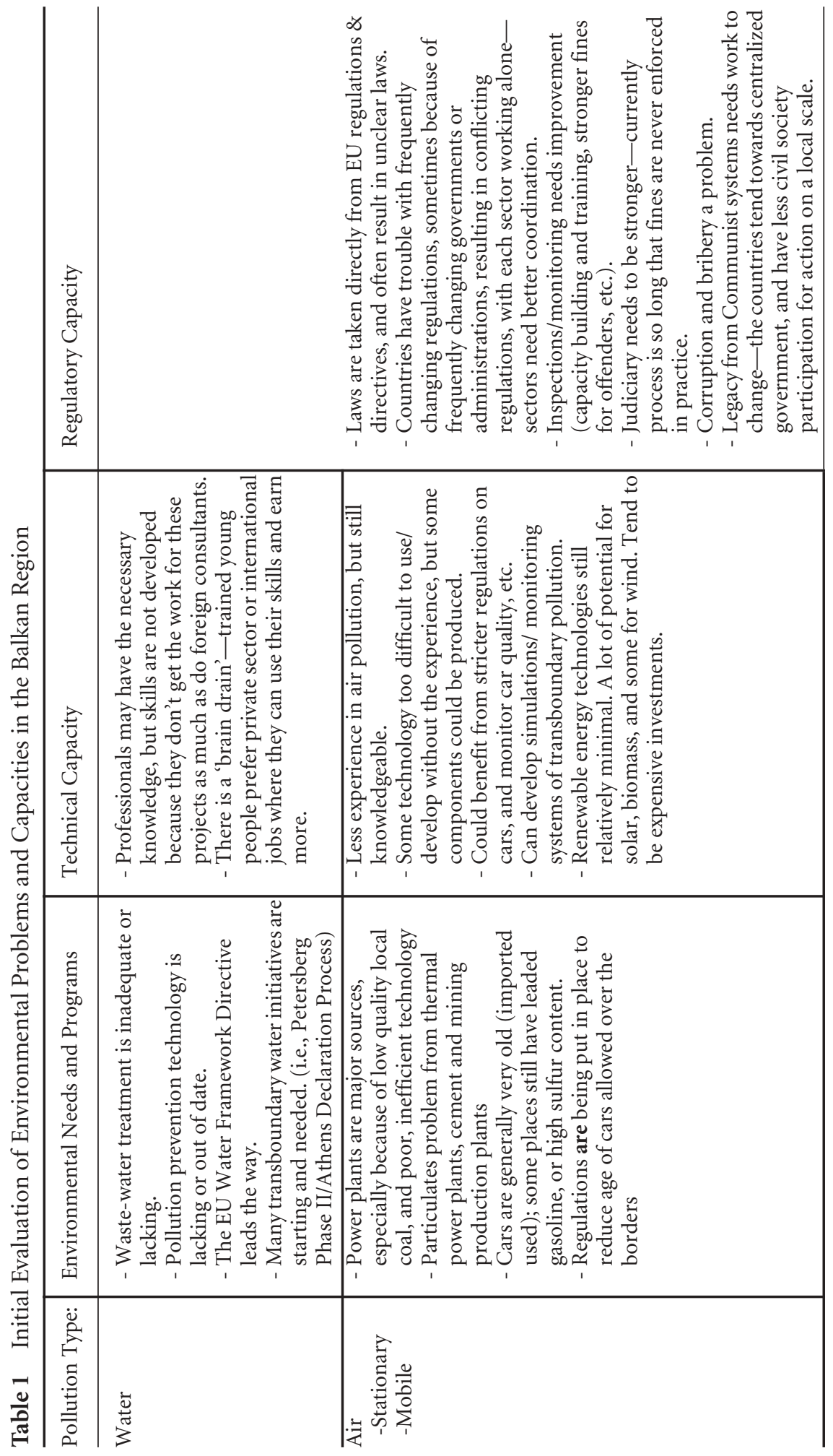




\begin{tabular}{|c|c|c|c|}
\hline 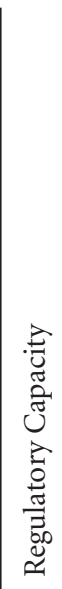 & \multicolumn{3}{|c|}{ 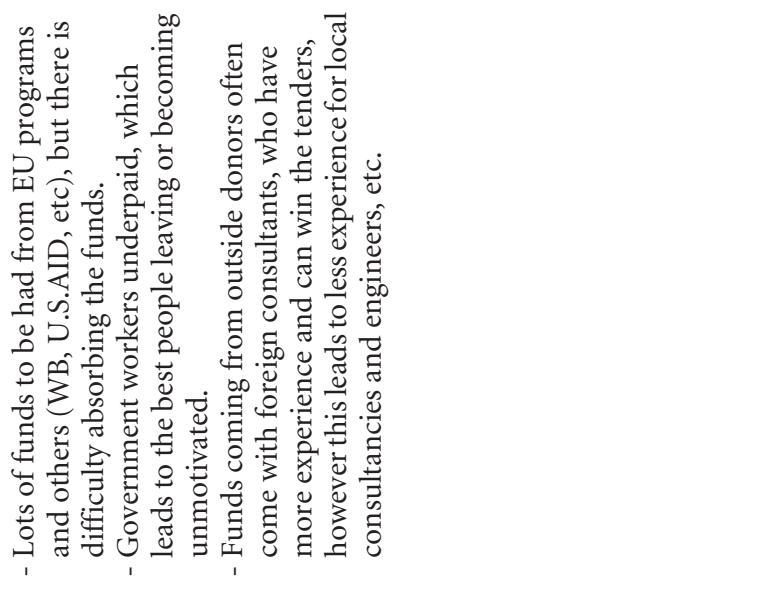 } \\
\hline 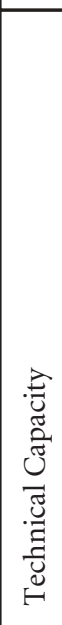 & 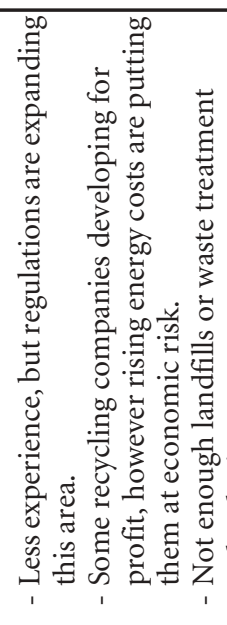 & 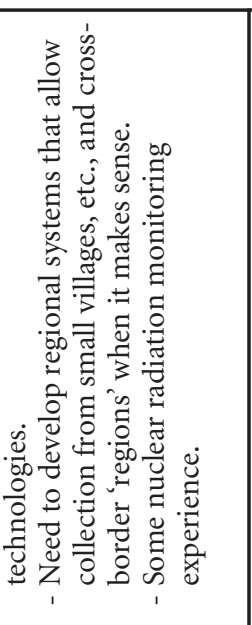 & 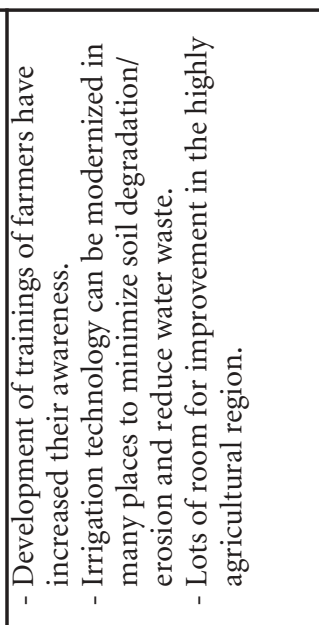 \\
\hline 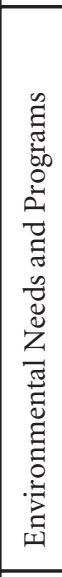 & 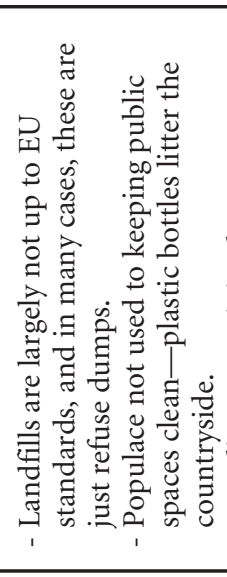 & 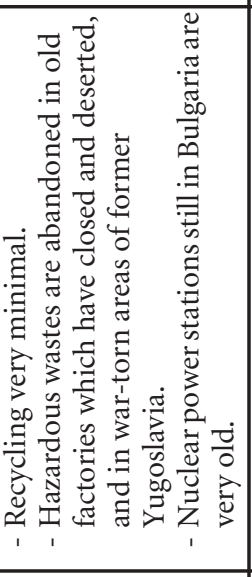 & 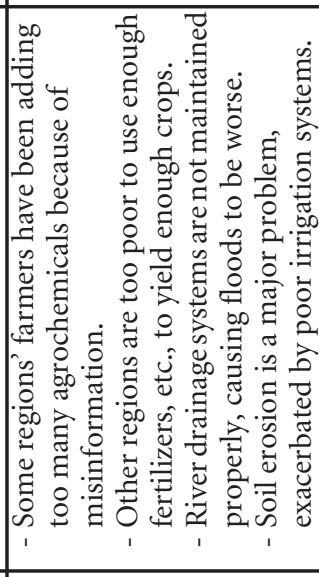 \\
\hline 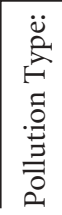 & 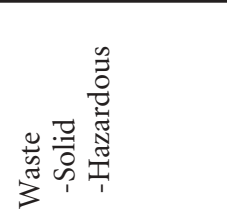 & & 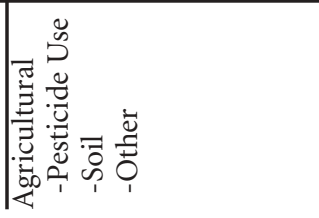 \\
\hline
\end{tabular}


initiative. It will also assess the potential role of ITCB as an integrating force for the sometimes fragmented assistance efforts of organizations such as the EU, and the United States and other individual country partnerships. The primary research objectives will be to:

- Identify key technical environmental problems related to agricultural and industrial activities in the Balkans.

- Identify and evaluate technological capabilities, capacities and gaps to address those problems within those Balkan countries.

- Assess the areas in which Greece has the technological capacity to serve as a provider of technological assistance, either on its own or in partnership with the United States.

- Describe and evaluate the regulatory infrastructure in the Balkan countries.

- Design a Balkan-wide coordinated governance plan for managing environmental improvement though technology and knowledge transfer, and regional and national regulatory systems.

- Identify opportunities for American-Greek cooperation in facilitating such a plan.

- Identify opportunities to coordinate the plan with other present efforts (internationally and among donor initiatives) towards environmental problem identification and solution.

In addition to the ITCB goals for the project, there will be cooperation with the Global Water Partnership-Mediterranean (GWP-Med) with respect to a new study they are undertaking on selected water basins of the Balkans. Together, in association with the Petersberg Phase II/Athens Declaration Process, the ITCB and GWP-Med will develop a case study regarding the technical and institutional needs for improving water management and pollution prevention in the Mesta/Nestos transboundary river basin between Bulgaria and Greece, and use this experience to make recommendations for the broader Southeastern European region. This study is in its initial phase and will last several years. The ITCB involvement will be through the environmental technology assessment of the factors affecting the same water basins that the GWP-Med project will focus upon. The results of this study will be presented to the EU and the American and Greek governments. Having been considered by the political processes for each respective government, recommendations for development aid and investment opportunities in the Southeastern European region will be made. The study, as well as the Unified Environmental Technology Plan for the Balkans, will eventually be available on the ITCB websites. 